\title{
Frequent Loss of the BLID Gene in Early-Onset Breast Cancer
}

\author{
L.R. Cavallia $\quad$ A.-M. Noone ${ }^{b} \quad$ K.H. Makambi ${ }^{\text {b }} \quad$ J.D. Rone ${ }^{a}$ U.N. Kasid ${ }^{c}$ \\ B.R. Haddad ${ }^{a, d}$
}

Departments of a Oncology, ${ }^{b}$ Biostatistics and Bioinformatics, ${ }^{c}$ Radiation Medicine, Biochemistry and Molecular and Cellular Biology, and ${ }^{\mathrm{d} O b s t e t r i c s}$ and Gynecology, Lombardi Comprehensive Cancer Center, Georgetown University Medical Center, Washington, D.C., USA

\section{Key Words}

BLID gene $\cdot$ Early-onset breast cancer $\cdot$ Loss of heterozygosity
Breast cancer is the most common cancer in women and the second leading cause of cancer death. Lymph node involvement, tumor size, histology, and hormone receptor status are the main prognostic factors used in breast cancer, even though the heterogeneous nature of the disease makes the prediction of recurrence difficult. Although breast cancer risk increases with age, the disease is more aggressive in women 40 years old or younger (early onset). Younger women are faced with a poorer prognosis, worse disease-free survival, higher mortality, and increased risk of recurrence even when controlling for stage, treatment and race [Chung et al., 1996; Sinha et al., 2008; Fredholm et al., 2009; Gnerlich et al., 2009; Sariego, 2010].

The more aggressive clinical picture in early-onset breast cancer as compared to later-onset disease includes larger tumor size, presence of positive lymph nodes, absence of steroid receptors, and high S-phase fraction, suggesting that young age may by itself be an independent factor for a poor outcome. Therefore, it stands to reason that identification of genes involved in the initiation and progression of early-onset breast cancer, correlation between alterations in these genes (e.g. loss of function, amplification) and outcome (e.g. response to therapy, survival) will improve our understanding of the disease and possibly its management in this age group. Loss of heterozygosity $(\mathrm{LOH})$ studies are often used to investigate chro-

\section{KARGER}

๑) 2011 S. Karger AG, Basel

Fax +4161306 1234

E-Mail karger@karger.ch

www.karger.com
Accessible online at: www.karger.com/cgr
Dr. Bassem R. Haddad

Georgetown University

3800 Reservoir Road, NW, Lower Level Lombardi Building, S-111

Washington, DC 2007 (USA)

Tel. +1 202444 0759, E-Mail haddadb1@ georgetown.edu 
mosomal deletions and identify possible regions harboring tumor suppressor genes [Wang et al., 2004; Rothenberg and Settleman, 2010]. LOH studies have shown extensive loss at 11q24-q25 in early-onset breast cancer and a significant association with poor prognosis and reduced survival [Gentile et al., 1999, 2001a, b; Chunder et al., 2004; Climent et al., 2007]. The high frequency of LOH at chromosome 11q24.1-11q25 in early-onset breast cancer and the association of this loss with poor prognosis of breast and ovarian neoplasias suggest that this chromosomal region may harbor putative tumor suppressor gene(s) [Ferti-Passantonopoulou et al., 1991; Gabra et al., 1996; di Iasio et al., 1999; Gentile et al., 1999, 2001a, b; Agrup et al., 2000; Choi et al., 2003; Weber-Mangal et al., 2003; Chunder et al., 2004; Jong et al., 2004; Climent et al., 2007].

BH3-like motif-containing inducer of cell death (BLID; alias BRCC2) is an intronless gene localized at 11q24.1 [Cavalli et al., 2008], an area of extensive LOH in cancer. This gene was first discovered in MDA-MB 231 human breast carcinoma cells as an approximately $1.2-\mathrm{kb}$ transcript (GenBank accession numbers AF220061 and AF303179) [Broustas et al., 2004]. The longest predictive open reading frame (ORF) of BLID (327 bp) codes for an approximately $12-\mathrm{kDa}$ protein (108 aa) localized predominantly in the cytosol and to a lesser extent in the mitochondria. Ectopic expression of BLID cDNA was also found in both the cytosol and mitochondria, and BLID was found to have a negative impact on cell survival. Functional studies have identified BLID as a novel BH3like domain containing a pro-apoptotic molecule [Broustas et al., 2010]. Exogenous expression of BLID caused apoptotic cell death in 3 different cell lines (monkey kidney cells, COS-1; human prostate carcinoma cells, PC-3; and human cervical carcinoma cells, ME-180), as evidenced by enhanced chromatin condensation, DNA fragmentation or enhanced number of cells in the sub-G1 phase [Broustas et al., 2004]. Translocation of endogenous BLID to the mitochondria is increased in response to doxorubicin and hydrogen peroxide, known cytotoxic agents. Recently, BLID has been identified as a new binding partner of BCL- $\mathrm{X}_{\mathrm{L}}$, and BLID-induced apoptosis has been associated with activation of BAX and an increase in cytosolic cytochrome c [Broustas et al., 2010]. Unlike most other pro-apoptotic members of the BCL2 family, $B L I D$ is unique, as it appears to be an emerging prognostic and therapeutic target in breast cancer. Downregulation of BLID expression was correlated with poor prognostic factors including younger age (median 40 years), African American ethnicity, tumor size, disease-free and overall survival, and triple-negative disease [Broustas et al., 2010].

Since somatic loss is one of the key features of tumor suppressor genes, we designed this study to determine the incidence of BLID loss in a series of 78 invasive sporadic breast tumors and the association of this loss with earlyonset disease. The high frequency of $\mathrm{LOH}$ at chromosome 11q24.1-11q25 in early-onset breast cancer and the association of this loss with poor prognosis strongly suggest a role for the pro-apoptotic molecule, $B L I D$, located on 11q24.1, as a tumor suppressor gene in breast cancer; loss of this gene may contribute to the development of early-onset breast cancer in women 40 years old and younger. A better understanding of the mechanisms of tumorigenesis in early-onset breast cancer may lead to better treatment strategies and improved survival in younger women.

\section{Material and Methods}

We determined allelic loss of BLID by LOH analysis of breast tissue specimens from 78 patients with sporadic breast cancer obtained from the tumor bank of the Histopathology and Tissue Shared Resources (HTSR) of Georgetown University Lombardi Comprehensive Cancer Center (LCCC). In each case, a paraffin block with breast tumor tissues and a second block with normal tissues (skin, negative lymph node or a normal breast tissue nonadjacent to the tumor to avoid potential field effect of genetic abnormalities) were identified. An H\&E (hematoxylin/eosinstained) slide from each block was evaluated by a pathologist to confirm the diagnosis and mark the areas with malignant tissue or normal tissue. A $100-\mu \mathrm{m}$ consecutive section was obtained from each block, and the tissues of interest were grossly microdissected with a razor blade to insure that over $90 \%$ of the sample consisted of malignant cells. Corresponding normal cells from a different block from the same patient were obtained for each case. DNA was extracted from the tissue using the DNeasy kit (Qiagen Inc., Valencia, Calif., USA) according to the manufacturer's instructions. For the purpose of this study, we defined early-onset breast cancer as cancer occurring at the age of 40 years and younger.

To study $\mathrm{LOH}$ at the BLID locus, we selected 2 dinucleotide polymorphic markers closely linked to, and flanking, the BLID gene because there are no intragenic markers for BLID: D11S4107 $(120,554,216-120,554,534)$ and D11S4167 (121,655,531121,655,846) (BLID: 121,491,272-121,492,133). These 2 markers have a high degree of heterozygosity. The sequences of the oligonucleotide primers were obtained from the UCSC genome database (http://www.genome.ucsc.edu). Primers were fluorescently labeled, and PCR amplification was performed using a standard protocol. Allele sizes were determined by electrophoresis of PCR products in $6 \%$ denaturing polyacrylamide gels and compared to ROX 500 size standards (Applied Biosystems, Foster City, Calif., USA), using an automated sequencer (ABI 377), according to the manufacturer's instructions (Applied Biosystems). Fluorescent 


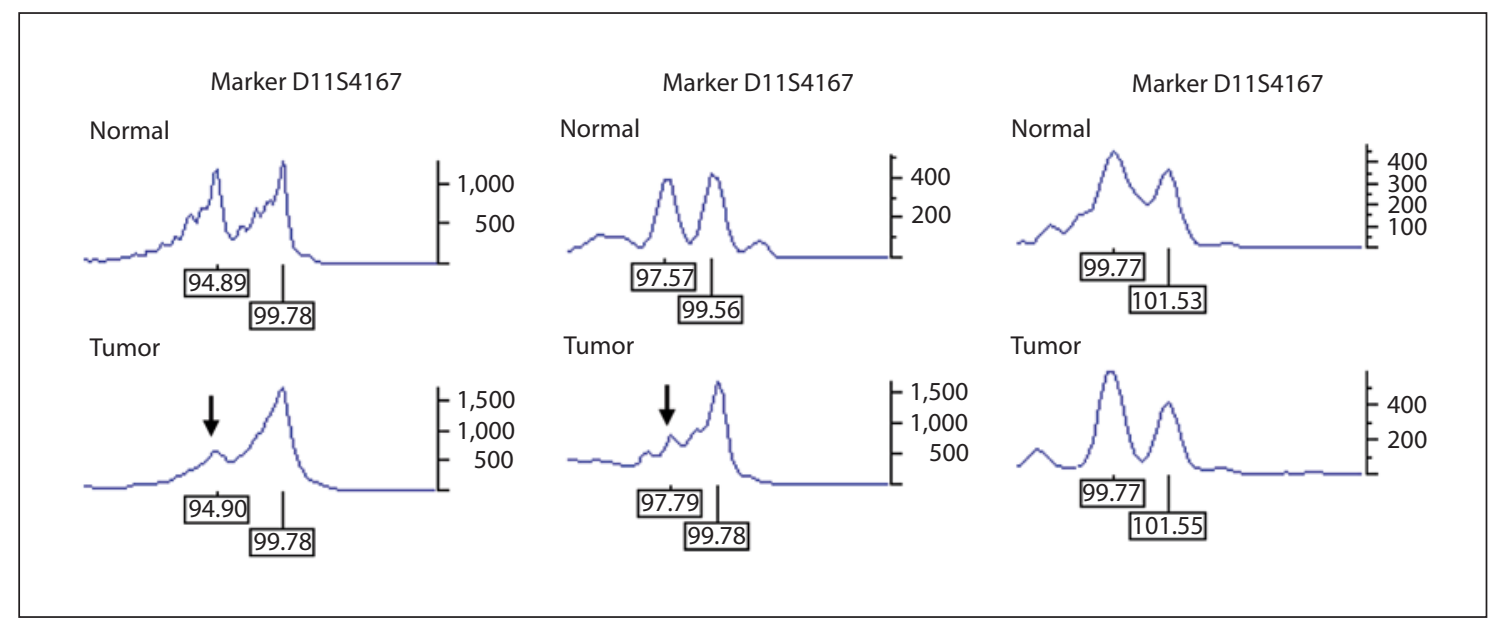

Fig. 1. Two representative cases with $\mathrm{LOH}$ (left and middle panels) and another representative case with no $\mathrm{LOH}$ (right panel) for marker D11S4167. In each case, the arrow indicates the lost allele.

Table 1. Patient characteristics by LOH status and unadjusted and adjusted odds ratios modeling the probability of loss

\begin{tabular}{|c|c|c|c|c|c|c|c|c|c|c|c|c|}
\hline & \multicolumn{2}{|c|}{$\begin{array}{l}\text { Total } \\
(n=73)\end{array}$} & \multicolumn{2}{|c|}{$\begin{array}{l}\mathrm{LOH} \\
(\mathrm{n}=23)\end{array}$} & \multicolumn{2}{|c|}{$\begin{array}{l}\text { No LOH } \\
(n=50)\end{array}$} & \multicolumn{3}{|c|}{ Unadjusted } & \multicolumn{3}{|c|}{ Adjusted } \\
\hline$\leq 40$ & 18 & $25 \%$ & 9 & $50 \%$ & 9 & $50 \%$ & 3.7 & $1.1-13$ & 0.04 & 3.5 & $1.0-12$ & 0.05 \\
\hline $41-55$ & 33 & $45 \%$ & 7 & $21 \%$ & 26 & $79 \%$ & ref & & & ref & & \\
\hline$\geq 56$ & 22 & $30 \%$ & 7 & $32 \%$ & 15 & $68 \%$ & 1.7 & $0.5-5.9$ & 0.38 & 1.9 & $0.5-6.7$ & 0.31 \\
\hline I & 27 & $37 \%$ & 6 & $22 \%$ & 21 & $78 \%$ & ref & & & ref & & \\
\hline II-IV & 46 & $63 \%$ & 17 & $37 \%$ & 29 & $63 \%$ & 2.1 & $0.7-6.1$ & 0.20 & 1.9 & $0.6-6.0$ & 0.26 \\
\hline
\end{tabular}

* Odds ratios describe univariable associations, modeling probability of loss. ${ }^{*}$ Odds ratios describe adjusted multivariable associations, modeling probability of loss. Referent category is denoted (ref).

signals from the different-sized alleles were recorded and analyzed using GENOTYPER version 2.1 and GENESCAN version 3.1 software (Applied Biosystems), respectively. Following visual examination of computer printouts by 2 independent observers, $\mathrm{LOH}$ was determined mathematically according to the Genotyper User's Manual (Applied Biosystems).

Patient characteristics were age $(\leq 40,41-55, \geq 56)$ and disease stage (I, II-IV) (table 1). Logistic regression was used to evaluate the association between age and stage with $\mathrm{LOH}$ and to provide unadjusted and adjusted odds ratios (OR) and 95\% confidence intervals for these predictors of interest. Statistical analyses were performed using SAS statistical software, version 9.2 (SAS Institute, Inc., Cary, N.C., USA).

\section{Results}

In this study, $73 / 78$ cases (94\%) were informative for the BLID dinucleotide markers used for $\mathrm{LOH}$ analysis. $\mathrm{LOH}$ was detected in 23 of these informative cases (23/73; $32 \%)$. Figure 1 shows LOH analysis at marker D11S4167. Two representative cases with LOH (left and middle panels) and another representative case with no $\mathrm{LOH}$ (right panel) are shown. In each case with $\mathrm{LOH}$, the arrow indicates the lost allele. Patient characteristics and $\mathrm{LOH}$ results are summarized in table 1 . Fifty percent of the patients with early-onset disease (age $\leq 40$ ) had LOH, as opposed to $21 \%$ and $32 \%$ in the $41-55$ and $\geq 56$ age 
groups, respectively. In addition, early-onset patients were significantly more likely to experience $\mathrm{LOH}$ at the BLID locus than those aged $41-55$ ( $\mathrm{p}=0.04$; table 1$)$. Specifically, the odds of loss for early-onset patients were 3.7 times the odds of loss for patients aged 41-55 (95\% CI, 1.1-13). Odds of loss for patients 56 years and older were not significantly different from either the early-onset or the $41-55$ age group.

$\mathrm{LOH}$ in tumors from patients with stage I disease was observed in $22 \%$ of the cases versus $37 \%$ of the tumors from patients with later-stage disease (stages II-IV). A test for the association between $\mathrm{LOH}$ and age yielded nonsignificant results ( $\chi^{2}$ test, $\mathrm{p}=0.88$ vs. $\mathrm{p}=0.06$ for early and late stage, respectively). Therefore, stage seems to play a nonsignificant role in this relationship. In the early-onset group, $78 \%$ of the cases were of late stage compared to $58 \%$ of the cases in the late-onset group ( $\chi^{2}$ test, $\mathrm{p}=0.14$ for the association between stage and age). After adjusting for stage, the odds of loss for early-onset patients compared to patients aged 41-55 was slightly attenuated but remained statistically significant $(\mathrm{OR}=3.5$, $95 \% \mathrm{CI}, 1.0-12, \mathrm{p}=0.05)$.

\section{Discussion}

Chromosomal deletions involving 11q is frequent in a number of different tumor types [Spitz et al., 2006; Watanabe et al., 2006; Parikh et al., 2007; Buckley et al., 2010; Fischer et al., 2010] and are associated with poor prognostic features. Recent studies on neuroblastoma, where allelic losses on 11q occur in approximately $30 \%$ of the tumors, reported that tumors with 11q loss are a distinct subgroup with different clinical and genetic behavior, as determined by array-CGH and gene expression (miRNA) analysis [Buckley et al., 2010; Fischer et al., 2010]. LOH is a powerful tool to identify areas that might harbor tumor suppressor genes. A high frequency of $\mathrm{LOH}$ has been reported at the 11q23-q24 region [Gudmundsson et al., 1995; Martin et al., 2003; Wang et al., 2004; Climent et al., 2007]. In this study, we observed LOH at 2 microsatellite markers closely linked and flanking the BLID gene on $11 \mathrm{q} 24.1$ in $50 \%$ of breast tumors from patients with earlyonset disease (age $\leq 40$ ), compared to 21 and $32 \%$ of tumors from patients in the 41-55-year-old and $\geq 56$-yearold groups, respectively. In addition, the odds of $B L I D$ loss for patients 40 years and younger were 3.7 times the odds of loss for patients aged 41-55 (95\% CI, 1.1-13). Despite the fact that one of the limitations of our study is the small sample size, our findings are consistent with other studies from our group showing that downregulation of the BLID protein was correlated with younger age (median 40 years), large tumor size, and decreased diseasefree and overall survival, all factors of poor prognosis [Broustas et al., 2010]. In spite of the heterogeneous nature of breast cancer and the variation in incidence among age groups in different countries, studies have shown that breast cancer diagnosed at a younger age is associated with a worse prognosis and that this subset of tumors shares similar patterns of gene expression that are different than tumors from older patients [Chunder et al., 2004; Elkum et al., 2007; Anders et al., 2008a, b; Fredholm et al., 2009; Gnerlich et al., 2009].

Other studies in early-onset breast tumors support our present data, reporting frequent allelic losses on chromosome 11q. Gudmundsson et al. [1995] found 3 distinct regions of $\mathrm{LOH}$ on chromosome 11 in breast cancer patients of young age, with the highest frequency of $\mathrm{LOH}$ $(37-43 \%)$ at 11q22-qter. Loss of the whole arm of this chromosome was found in $20 \%$ of early-onset cases $(<35$ years old, $\mathrm{n}=44$ ) compared to $7.4 \%$ of late-onset cases ( $>63$ years old, $n=54$ ) by Jong et al. [2004]. Frequent allelic deletions were reported at chromosome 11q23-q24 in approximately $50 \%$ of breast cancer tissues from mixed populations [Ferti-Passantonopoulou et al., 1991; di Iasio et al., 1999; Wang et al., 2004] and at 11q23-q25 in 11\% of breast cancer tissues from women younger than 35 years [Weber-Mangal et al., 2003]. A compelling evidence for involvement of 11q (11q24.1-q25) in breast cancer in younger women $(22-36$ years old at diagnosis, $\mathrm{n}=102$ ) was provided by Gentile et al. [2001a]. In this study, LOH frequencies for the 3 markers in the 11q24.1-q25 region ranged from $51-54 \%$. Loss at the most centromeric marker (D11S969) was associated with a high histological grade $(\mathrm{p}=0.02)$. Two markers in the $11 \mathrm{q} 25$ region (D11S387 and D11S4125) exhibited LOH frequencies of 42 and 53\%, respectively. Additional studies of $\mathrm{LOH}$ on $11 \mathrm{q}$ in early- and late-onset breast cancer were reported by Chunder et al. [2004]. This group described 6 highly deleted regions on chromosome 11 in younger and older breast cancer patients, namely 11p15.5, 11p11.2, 11q13.2, 11q22.3-23.1, 11q23.1-24.1, and 11q25. They also observed that the pattern of associations between these deletions and the amplification of the CCND1 gene, mapped at 11q13, differed between age groups.

Genomic loss at the 11q23 region in early-onset breast cancer patients was associated with increased sensitivity to anthracycline treatment [Climent et al., 2007]. The presence of genes mapped to this region, CHK1, H2A, ATM, and $Z W 10$, which are involved in DNA repair pathways, 
suggests that deletions on $11 \mathrm{q}$ can lead to a functional impairment of these genes in early-onset breast cancer cases.

MicroRNA (miRNA) analysis demonstrated that deletions on 11q can also target noncoding miRNAs [Iorio et al., 2005]. The miR125b-1, which maps very closely to the BLID gene, has been found to be downregulated in breast tumors with 11q deletions. This miRNA may potentially regulate oncogenes such as ETS1, which plays a role in cell growth and is overexpressed in breast cancer. Other miRNAs closely mapped to the BLID gene are the mirLet7-a-2 and miR100. Overexpression of miR100 was linked to low expression of the ATM gene in a glioma cell line [Ng et al., 2010]. Other studies have identified alterations in miRNAs, such as miR146a, miR-453 and miR502 , to be associated with early-onset breast tumors [Song et al., 2009; Tchatchou et al., 2009; Pastrello et al., 2010].

All of these studies point to a hot spot of activity on $11 \mathrm{q}$ region and suggest that chromosomal loss in this region is implicated in the development of early-onset breast cancer. The idea that a chromosomal region may be the site of a potential 'tumor suppressor gene cluster' has been described for the 3p21.3 region [Ji et al., 2005] and may also apply to the telomeric region of chromo- some 11q. In this respect and based on the findings of this study as well as other studies from our group [Broustas et al., 2010], we propose that the BLID gene located in this hot spot plays a relevant role in this group of patients. However, additional studies are needed to determine the incidence and type of BLID mutations. There is a definite need to identify markers for earlier detection and more targeted therapies in early-onset breast cancer patients who have poorer outcomes and higher mortality rates than older women. The BLID gene can potentially be one of these markers.

\section{Acknowledgements}

This work was supported by the Susan G. Komen Breast Cancer Foundation (BCTR0503829) to B.R.H. The breast tumor tissues were obtained from the tumor bank of the Histopathology and Tissue Shared Resources (HTSR) of Georgetown University Lombardi Comprehensive Cancer Center, which is partially supported by NIH/NCI (P30-CA51008-10), Cancer Center Support Grant (CCSG), to the Lombardi Comprehensive Cancer Center.

\section{References}

Agrup M, Stal O, Olsen K, Wingren S: C-erbB-2 overexpression and survival in early onset breast cancer. Breast Cancer Res Treat 63: 23-29 (2000).

-Anders CK, Hsu DS, Broadwater G, Acharya CR, Foekens JA, et al: Young age at diagnosis correlates with worse prognosis and defines a subset of breast cancers with shared patterns of gene expression. J Clin Oncol 26:33243330 (2008a).

-Anders CK, Acharya CR, Hsu DS, Broadwater G, Garman K, et al: Age-specific differences in oncogenic pathway deregulation seen in human breast tumors. PLoS One 3:e1373 (2008b).

-Broustas C, Gokhale P, Rahman A, Dritschilo A, Ahmad I, Kasid U: BRCC2, a novel BH3-like domain-containing protein, induces apoptosis in a caspase-dependent manner. J Biol Chem 279:26780-26788 (2004).

-Broustas CB, Ross JS, Yang Q, Sheehan CE, Riggins $\mathrm{R}$, et al: The proapoptotic molecule BLID interacts with $\mathrm{Bcl}-\mathrm{X}_{\mathrm{L}}$ and its downregulation in breast cancer correlates with poor disease-free and overall survival. Clin Cancer Res 16:2939-2948 (2010).

-Buckley PG, Alcock L, Bryan K, Bray I, Schulte $\mathrm{JH}$, et al: Chromosomal and microRNA expression patterns reveal biologically distinct subgroups of 11q- neuroblastoma. Clin Cancer Res 16:2971-2978 (2010).
Cavalli LR, Santos SC, Broustas CG, Rone JD, Kasid UN, Haddad BR: Assignment of BLID gene to $11 \mathrm{q} 24.1$ by FISH. Cancer Genet Cytogenet 186:120-121 (2008).

Choi DH, Shin DB, Lee MH, Lee DW, Dhandapani $\mathrm{D}$, et al: A comparison of five immunohistochemical biomarkers and HER-2/neu gene amplification by fluorescence in situ hybridization in white and Korean patients with early-onset breast carcinoma. Cancer 98:1587-1595 (2003)

Chunder N, Mandal S, Roy A, Roychoudhury S, Panda CK: Analysis of different deleted regions in chromosome 11 and their interrelations in early- and late-onset breast tumors: association with CYCLIN D1 amplification and survival. Diagn Mol Pathol 13:172-182 (2004).

Chung M, Chang HR, Bland KI, Wanebo HJ: Younger women with breast carcinoma have a poorer prognosis than older women. Cancer 77:97-103 (1996).

Climent J, Dimitrow P, Fridlyand J, Palacios J, Seiebert R, et al: Deletion of chromosome 11q predicts response to anthracycline-based chemotherapy in early breast cancer. Cancer Res 67:818-826 (2007). di Iasio MG, Calin G, Tibiletti MG, Vorechovsky I, Benediktsson KP, et al: Refinement of the $\mathrm{LOH}$ region 1 at 11q23.1 deleted in human breast carcinomas and sublocalization of 11 expressed sequence tags within the refined region. Oncogene 18:1635-1638 (1999).

Elkum N, Dermime S, Ajarim D, Al-Zahrani A Alsayed A, et al: Being 40 or younger is an independent risk factor for relapse in operable breast cancer patients: the Saudi Arabia experience. BMC Cancer 7:222 (2007).

Ferti-Passantonopoulou A, Panani AD, Raptis S: Preferential involvement of 11q23-24 and 11 15 in breast cancer. Cancer Genet Cytogenet 51:183-188 (1991).

-Fischer M, Bauer T, Oberthür A, Hero B, Theissen J, et al: Integrated genomic profiling identifies two distinct molecular subtypes with divergent outcome in neuroblastoma with loss of chromosome 11q. Oncogene 29:865-875 (2010).

Fredholm H, Eaker S, Frisell J, Holmberg L, Fredriksson I, Lindman $\mathrm{H}$ : Breast cancer in young women: poor survival despite intensive treatment. PLoS One 4:e7695 (2009).

Gabra H, Watson JE, Taylor KJ, Mackay J, Leonard $\mathrm{RC}$, et al: Definition and refinement of a region of loss of heterozygosity at 11q23.3q24.3 in epithelial ovarian cancer associated with poor prognosis. Cancer Res 56:950-954 (1996). 
Gentile M, Olsen K, Dufmats M, Wingren S: Frequent allelic losses at 11q24.1-q25 in young women with breast cancer: association with poor survival. Br J Cancer 80:843-849 (1999).

- Gentile M, Wiman A, Thorstenson S, Loman N, Borg A, Wingren S: Deletion mapping of chromosome segment 11q24-q25, exhibiting extensive allelic loss in early onset breast cancer. Int J Cancer 92:208-213 (2001a).

Gentile M, Ahnström M, Schön F, Wingren S: Candidate tumour suppressor genes at 11q23-q24 in breast cancer: evidence of alterations in $P I G 8$, a gene involved in p53-induced apoptosis. Oncogene 20:7753-7760 (2001b).

Gnerlich JL, Deshpande AD, Jeffe DB, Sweet A, White N, Margenthaler JA: Elevated breast cancer mortality in women younger than age 40 years compared with older women is attributed to poorer survival in early-stage disease. J Am Coll Surg 208:341-347 (2009).

- Gudmundsson J, Barkardottir RB, Eiriksdottir G, Baldursson T, Arason A, et al: Loss of heterozygosity at chromosome 11 in breast cancer: association of prognostic factors with genetic alterations. Br J Cancer 72:696-701 (1995).

- Iorio MV, Ferracin M, Liu CG, Veronese A, Spizzo R, et al: MicroRNA gene expression deregulation in human breast cancer. Cancer Res 65:7065-7070 (2005).

-Ji L, Minna JD, Roth JA:3p21.3 tumor suppressor cluster: prospects for translational applications. Future Oncol 1:79-92 (2005).
Jong YJ, Li LH, Tsou MH, Chen YJ, Cheng SH, et al: Chromosomal comparative genomic hybridization abnormalities in early- and lateonset human breast cancers: correlation with disease progression and TP53 mutations. Cancer Genet Cytogenet 148:55-65 (2004).

\section{Martin ES, Cesari R, Pentimalli F, Yoder K, Fish-} el R, et al: The BCSC-1 locus at chromosome $11 \mathrm{q} 23-\mathrm{q} 24$ is a candidate tumor suppressor gene. Proc Natl Acad Sci USA 100:1151711522 (2003).

Ng WL, Yan D, Zhang X, Mo YY, Wang Y: Overexpression of miR-100 is responsible for the low-expression of ATM in the human glioma cell line: M059J. DNA Repair (Amst) 9:11701175 (2010)

- Parikh RA, White JS, Huang X, Schoppy DW, Baysal BE, et al: Loss of distal 11q is associated with DNA repair deficiency and reduced sensitivity to ionizing radiation in head and neck squamous cell carcinoma. Genes Chromosomes Cancer 46:761-775 (2007).

Pastrello C, Polesel J, Della Puppa L, Viel A, Maestro R: Association between hsa-mir146a genotype and tumor age-of-onset in BRCA1/BRCA2-negative familial breast and ovarian cancer patients. Carcinogenesis 31: 2124-2126 (2010).

Rothenberg SM, Settleman J: Discovering tumor suppressor genes through genome-wide copy number analysis. Curr Genomics 11: 297-310 (2010).

Sariego J: Breast cancer in the young patient. Am Surg 76:1397-1400 (2010).

- Sinha S, Singh RK, Alam N, Roy A, Roychoudhury S, Panda CK: Frequent alterations of $h M L H 1$ and RBSP3/HYA22 at chromosomal 3 p22.3 region in early and late-onset breast carcinoma: clinical and prognostic significance. Cancer Sci 99:1984-1991 (2008).
Song F, Zheng H, Liu B, Wei S, Dai H, et al: An miR-502-binding site single-nucleotide polymorphism in the $3^{\prime}$-untranslated region of the SET8 gene is associated with early age of breast cancer onset. Clin Cancer Res 15: 6292-6300 (2009).

Spitz R, Hero B, Simon T, Berthold F: Loss in chromosome 11q identifies tumors with increased risk for metastatic relapses in localized and 4 S neuroblastoma. Clin Cancer Res 12:3368-3373 (2006).

Tchatchou S, Jung A, Hemminki K, Sutter C, Wappenschmidt B, et al: A variant affecting a putative miRNA target site in estrogen receptor (ESR) 1 is associated with breast cancer risk in premenopausal women. Carcinogenesis 30:59-64 (2009)

Wang ZC, Lin M, Wei LJ, Li C, Miron A, et al: Loss of heterozygosity and its correlation with expression profiles in subclasses of invasive breast cancers. Cancer Res 64:64-71 (2004).

Watanabe N, Nakadate H, Haruta M, Sugawara W, Sasaki F, et al: Association of 11q loss, trisomy 12 , and possible $16 \mathrm{q}$ loss with loss of imprinting of insulin-like growth factor-II in Wilms tumor. Genes Chromosomes Cancer 45:592-601 (2006).

-Weber-Mangal S, Sinn HP, Popp S, Klaes R, Emig R, et al: Breast cancer in young women ( $<$ or $=35$ years): genomic aberrations detected by comparative genomic hybridization. Int J Cancer 107:583-592 (2003). 